Research Article

\title{
Comparison of Three Analytical Methods for the Precise Calculation of Cogging Torque and Torque Ripple in Axial Flux PM Machines
}

\author{
Ahmed Hemeida, Bert Hannon, Hendrik Vansompel, and Peter Sergeant \\ Department of EESA, Electrical Energy Laboratory, Ghent University, Technologiepark-Zwijnaarde 913, 9052 Ghent, Belgium \\ Correspondence should be addressed to Ahmed Hemeida; a.hemeida@ieee.org
}

Received 20 June 2016; Revised 14 September 2016; Accepted 28 September 2016

Academic Editor: Dane Quinn

Copyright (C) 2016 Ahmed Hemeida et al. This is an open access article distributed under the Creative Commons Attribution License, which permits unrestricted use, distribution, and reproduction in any medium, provided the original work is properly cited.

\begin{abstract}
A comparison between different analytical and finite-element (FE) tools for the computation of cogging torque and torque ripple in axial flux permanent-magnet synchronous machines is made. 2D and 3D FE models are the most accurate for the computation of cogging torque and torque ripple. However, they are too time consuming to be used for optimization studies. Therefore, analytical tools are also used to obtain the cogging torque and torque ripple. In this paper, three types of analytical models are considered. They are all based on dividing the machine into many slices in the radial direction. One model computes the lateral force based on the magnetic field distribution in the air gap area. Another model is based on conformal mapping and uses complex Schwarz Christoffel (SC) transformations. The last model is based on the subdomain technique, which divides the studied geometry into a number of separate domains. The different types of models are compared for different slot openings and permanent-magnet widths. One of the main conclusions is that the subdomain model is best suited to compute the cogging torque and torque ripple with a much higher accuracy than the SC model.
\end{abstract}

\section{Introduction}

Thanks to its very good performance, the yokeless and segmented armature (YASA) machine, shown in Figure 1, has been used in many applications. Owing to the absence of the yoke, this machine provides a great power density and a low cost compared to other axial flux permanent-magnet synchronous machines (AFPMSMs) [1].

Cogging torque and torque ripple are some of the most important performance indicators in the design of electrical machines. It is important in any machine to keep these values as low as possible. Therefore, a large number of finite-element (FE) and analytical models have been developed to analyze these parameters.

Different techniques like permanent-magnet (PM) skewing, pole arc shifting, and optimized PM shapes are used to reduce the cogging torque and the torque ripple [2]. In addition, a proper selection of the slot opening might give an optimum performance in terms of cogging torque and the torque ripple [3]. The scope of this paper is to compare different modeling techniques based on their computational efficiency and accuracy.

Pulsations in torque occur due to two reasons. One reason is the harmonic contents of the stator's magnetomotive force (MMF); a second reason is the addition of spatial harmonic content due to the slots [4]. Therefore, modeling these two components is mandatory for the following comparison.

A 3D FE model is considered to be the most accurate model to predict the cogging torque and torque ripple [5]. However, such a model is a very time consuming. Faster 2D FE models are developed in [6]. These models consist of three steps. First the AFPMSM is divided into a number of slices in the radial direction. Secondly, the solution is obtained for each slice and finally the obtained solutions are combined using superposition. This type of models neglects the radial flux, which results in a less accurate solution. The authors in [7] developed a quasi-3D model that takes into account the end effect of the AFPMSMs. These models were used 


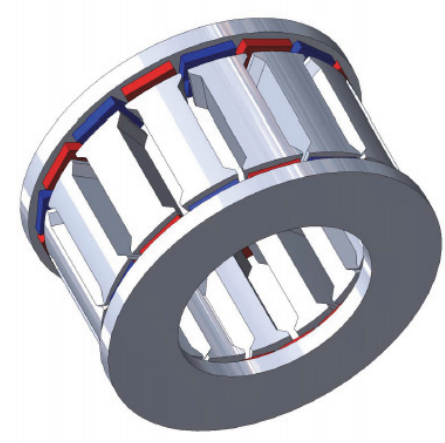

(a) Isometric view

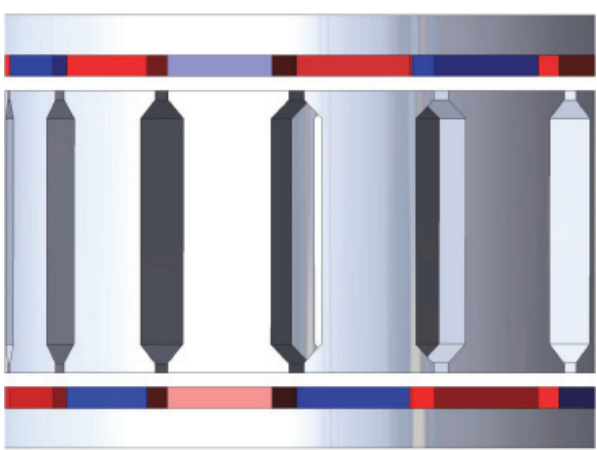

(b) Top view

FIgURE 1: The YASA topology of the axial flux PMSM.

afterwards in a more detailed investigation on cogging torque optimization in [8] using different PM shapes.

Although these quasi-3D models require less computational time than classic 3D models, their computational time consumption is still quite large. Therefore, analytical models are developed to obtain fast and accurate results. There are different concepts for analytical models, each of which requires an accurate computation of the flux density to calculate the torque. An overview of different analytical models concepts is described in [9]. These concepts can be divided into three categories.

The first category is based on obtaining the flux density due to permanent magnets and currents assuming a smooth, that is, slotless, half plane with infinite permeability, as in [10]. Afterwards, the slots are taken into account by introducing a permeance function of the slots. In [11], the slots are taken into account using a simple conformal mapping technique in radial-flux permanent-magnet synchronous machines (RFPMSMs). However, this method only computes the radial field component. It cannot predict the circumferential (tangential) field component and is therefore less accurate. This method, called the lateral force (LF) method, assumes that the force acting on the tooth surface is caused by the flux density variations beneath the surface of the slot opening.

The second category is based on [12]. The authors developed another permeance function based on conformal mapping. The mapping is done via a more complex Schwarz Christoffel (SC) transformation that is capable of obtaining both radial and tangential components of the flux density of the machine in both directions. The technique has been adopted in [13] to be used for AFPMSMs. This class of models is called SC models. Its most important disadvantage is that it neglects the interaction between neighboring slots.

The third category is based on the subdomain (SD) technique. The SD technique divides the geometry in a number of regions, called subdomains. In this technique, the slots are directly taken into account. In [14-17], the authors developed subdomain models for RFPMSMs. These models define the magnetic vector potential separately in the following domains: each slot, the air gap, and the PMs. The obtained vector potentials are linked to each other via suitable boundary conditions. The authors, in $[6,18]$, updated the model to be used for AFPMSMs with semiclosed slots. In [19], the authors developed a subdomain model of one slot and two PMs and made a superposition of all PMs and slots in the machine. All of the aforementioned authors have reported good accordance with FE calculations. In [20], a general formulation for the calculation of the flux density using the subdomain model is developed.

This model is applied in [13] and [21] for radial and axial flux PMSMs, respectively. The authors developed a hybrid analytical model of the subdomain model and reluctance network model that includes saturation effects.

A comparison between different models has been conducted in [22] for the calculation of cogging torque for RFPMSMs. In this paper, the subdomain model has been shown to be the most accurate model. However, the authors did not consider the mean torque and the torque ripple in their comparison. Moreover, they only consider the noload situation for their comparison. All methods can predict the radial component of the flux density. This results in an accurate calculation of the induced voltage. However, the circumferential flux density plays an important role in the calculation of the torque ripple and cogging torque.

In this paper, a complete investigation of the differences between various analytical and finite-element tools for the calculation of cogging torque and torque ripple in AFPMSMs is performed. The studied modeling techniques include the three aforementioned categories of analytical models and 2D and 3D FE models.

The paper is organized as follows. The FE and analytical models are discussed in Sections 2 and 3. The differences between these models for the calculation of the cogging torque and torque are then discussed in Section 4. Experimental validations are provided in Section 5. Finally, the work is concluded in Section 6.

\section{Description of the FE Models}

In this section, the $3 \mathrm{D}$ and $2 \mathrm{D}$ FE models are described and analyzed. The 3D FE model will serve as the reference solution to evaluate the accuracy of the other FE models. Its resulting no-load flux density distribution of the machine is shown in Figure 2. 


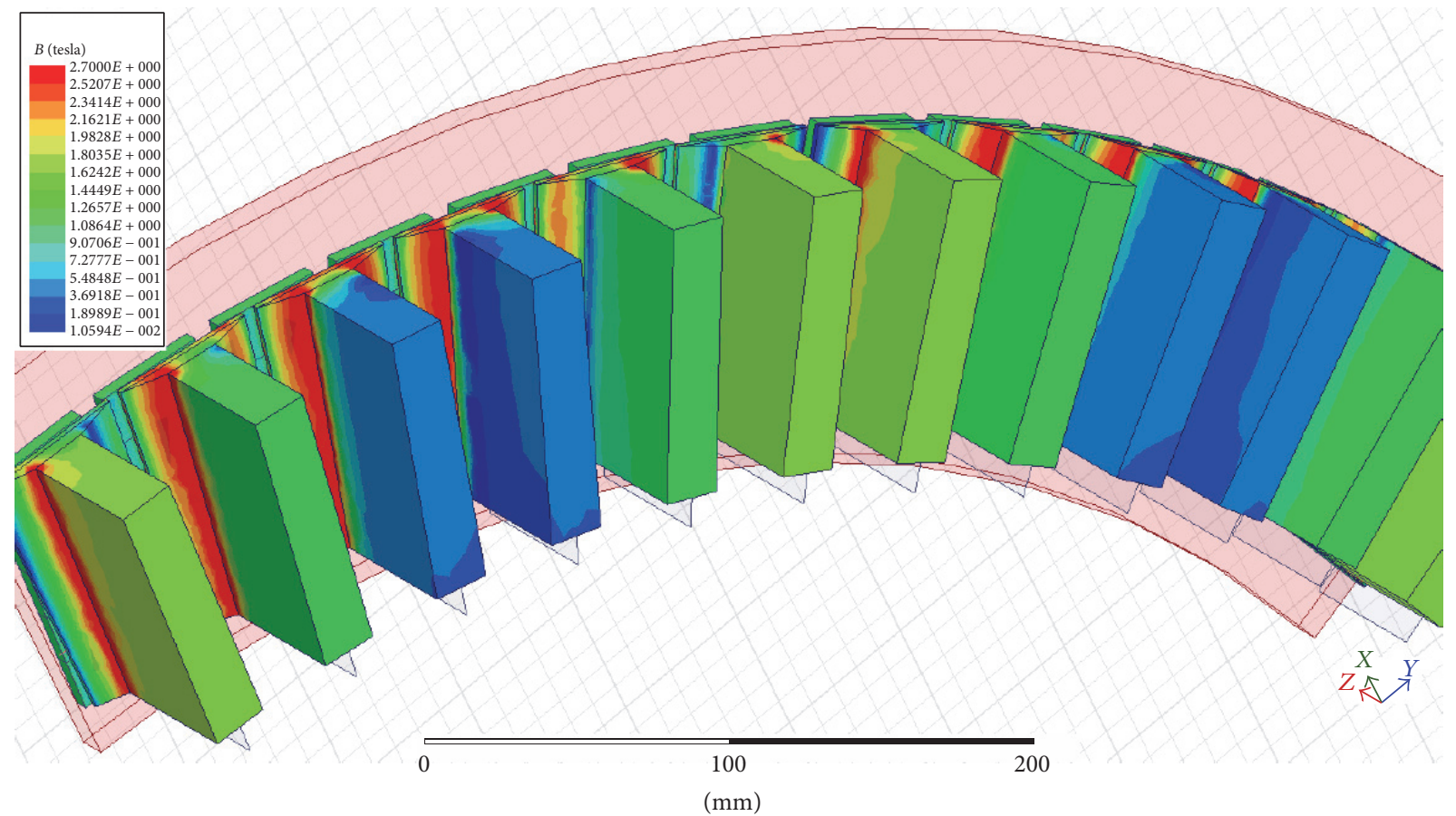

FIGURE 2: 3D field distribution of the machine at no load.

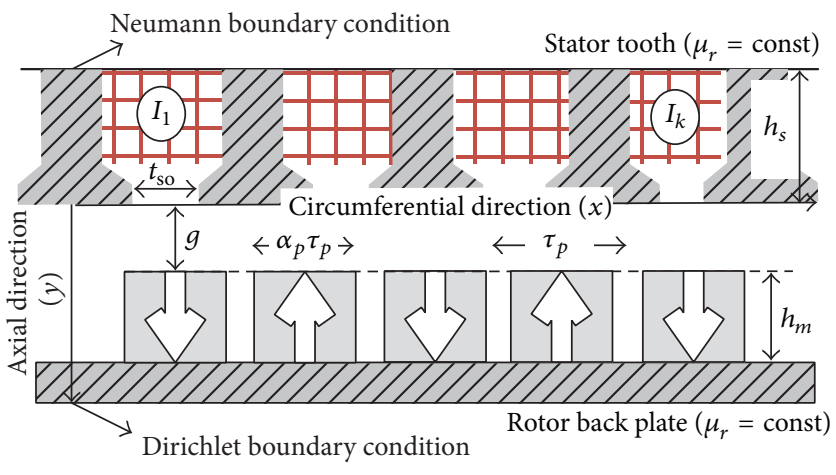

(a) 2D FE model with tooth tips

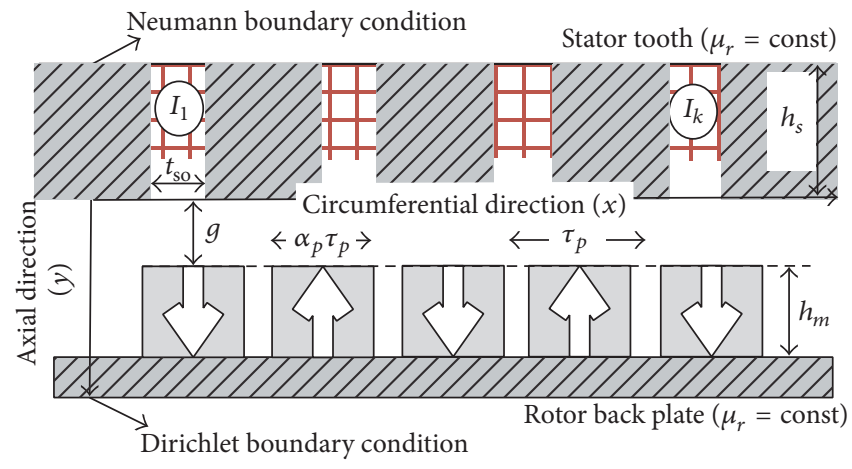

(b) 2D FE model without tooth tips

Figure 3: Different 2D FE models geometries and assumptions.

All analytical models are based on defining open slots without tooth tips. Of course, an important fraction of the electrical machines does have tooth tips. Therefore, two versions of the $2 \mathrm{D}$ FE model are considered, one with and one without tooth tips. Both 2D finite-element models are shown in Figures 3(a) and 3(b). The iron core permeability of both the 3D FE models and the 2D FE models is set to 10000 .

The no-load flux distribution of the 2D FE model is shown in Figure 4 for the geometry with tooth tips. Both 2D FE models use an extremely fine mesh in the air gap area, which results in a reliable solution for the torque ripple and cogging torque. The 2D FE model without tooth tips will be used as reference solution to compare the different analytical models.
The assumptions taken into account for all $\mathrm{FE}$ and analytical models are as follows:

(1) The permeability of the rotor and stator tooth is assumed to be constant for the FE models and infinite for the analytical model.

(2) The eddy currents in the PMs are neglected. The eddy currents can be reduced by segmenting the PMs as described in [23].

(3) The PMs have a constant recoil permeability of $\mu_{r}$.

Inherently, the AFPMSM results in a $3 \mathrm{D}$ problem. Both the 2D FE models and the analytical models cope with this issue by dividing the machine into $n_{s}$ different slices in the 


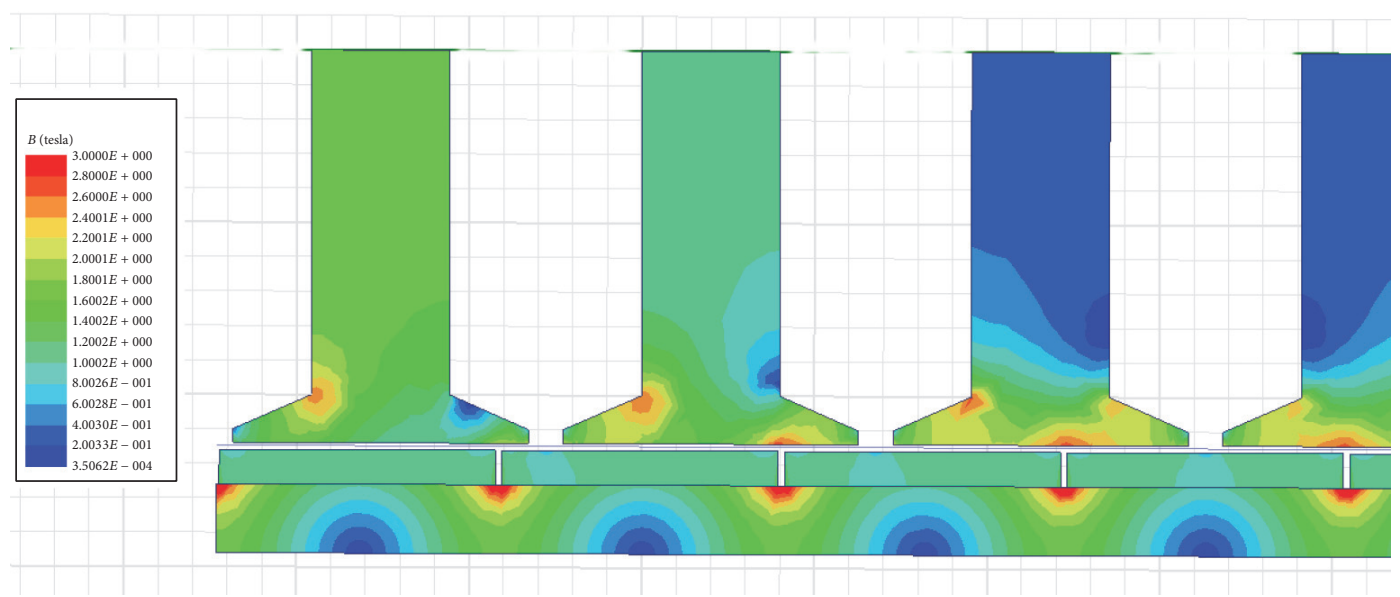

FIGURE 4: The 2D FE model flux distribution.

radial direction. Each slice $i$ has an average radius $R_{\mathrm{av}}^{i}$ and a width $t_{\mathrm{cp}}$. In all the 2D FE models, the radial component of the magnetic flux density is neglected. It was shown in [24] that the optimum number of slices is six. However, for an even better accuracy, this study models the machine via eight slices of the 2D FEM or the analytical model.

$$
\begin{aligned}
R_{\mathrm{av}}^{i} & =R_{i}+\frac{R_{o}-R_{i}}{n_{s}}\left(i-\frac{1}{2}\right), \quad i=1,2, \ldots, n, \\
t_{\mathrm{cp}} & =\frac{R_{o}-R_{i}}{n_{s}},
\end{aligned}
$$

where $R_{o}$ is the outer radius of the machine and $R_{i}$ is the inner radius. The torque $T$ is obtained by superposition over the different slices.

$$
T=\sum_{i=1}^{n_{s}} T_{i}
$$

The different FE and analytical models are illustrated using a $50 \mathrm{~kW}$ AFPMSM, its parameters are shown in Table 1. The PM used in this analysis is a rectangular shaped PM with a width $W_{\mathrm{pm}}$ and an axial length $Y_{m}$.

\section{Description of the Three Analytical Models}

3.1. Conformal Mapping Simple Model Applying Lateral Force Method (LF Model). This model is based on the conformal transformation discussed in [11]. It uses a simple SC transformation to predict the slotting effect; however it only accounts for the axial component of the resulting permeance function. This method results in an accurate solution for the predicted axial flux density. It is very simple compared to the other methods.

In a first step, the LF technique assumes smooth iron surfaces, as shown in Figure 5(a). The $M$ in Figure 5(b) represents the magnetization vector along the $x$-direction. The $x$-axis represents the distance in the circumferential direction. The $y$-axis denotes the distance in the axial direction, measured from the surface of the stator tooth.
TABle 1: Parameters of the designed machine.

\begin{tabular}{lccc}
\hline Parameter & Symbol & Value & Unit \\
\hline Rated power & $P_{n}$ & 50 & $\mathrm{~kW}$ \\
Rated speed & $n_{m}$ & 60 & $\mathrm{rpm}$ \\
Rated torque & $T_{\mathrm{FL}}$ & 8 & $\mathrm{kNm}$ \\
Outer diameter & $D_{o}$ & 1.1 & $\mathrm{~m}$ \\
Inner diameter & $D_{i}$ & 0.9 & $\mathrm{~m}$ \\
Slot opening & $t_{\mathrm{so}}$ & 8 & $\mathrm{~mm}$ \\
PM axial length & $Y_{m}$ & 5 & $\mathrm{~mm}$ \\
Air gap length & $g$ & 1 & $\mathrm{~mm}$ \\
PM width & $W_{\mathrm{pm}}$ & 40 & $\mathrm{~mm}$ \\
\hline
\end{tabular}

The amplitude of the Fourier-series expansion of the magnetization vector shown in Figure 5 can be obtained as follows:

$$
M_{n_{i}}=\frac{4 B_{r}}{n \pi \mu_{0}} \sin \left(\frac{n \pi \alpha_{p_{i}}}{2}\right),
$$

where $n$ is the harmonic order, $B_{r}$ is the remanent flux of the $\mathrm{PM}, \mu_{0}$ is the permeability of free space, and $\alpha_{p_{i}}$ is the PM width over pole pitch $\tau_{p_{i}}$ at slice number $i$.

This results in two field components, that is, $B_{x I_{i}}$ in the $x$-direction and $B_{y I_{i}}$ in the $y$-direction.

$$
\begin{aligned}
& B_{x I_{i}}(x, y)=\mu_{0} \sum_{n=1,3,5, \ldots}^{\infty} M_{n_{i}} \frac{\sinh \left(U_{n_{i}} Y_{m}\right)}{\Delta} \sinh \left(U_{n_{i}} y\right) \\
& \cdot \sin \left(U_{n_{i}} x\right), \\
& B_{y I_{i}}(x, y)=\mu_{0} \sum_{n=1,3,5, \ldots}^{\infty} M_{n_{i}} \frac{\sinh \left(U_{n_{i}} Y_{m}\right)}{\Delta} \cosh \left(U_{n_{i}} y\right) \\
& \cdot \cos \left(U_{n_{i}} x\right),
\end{aligned}
$$




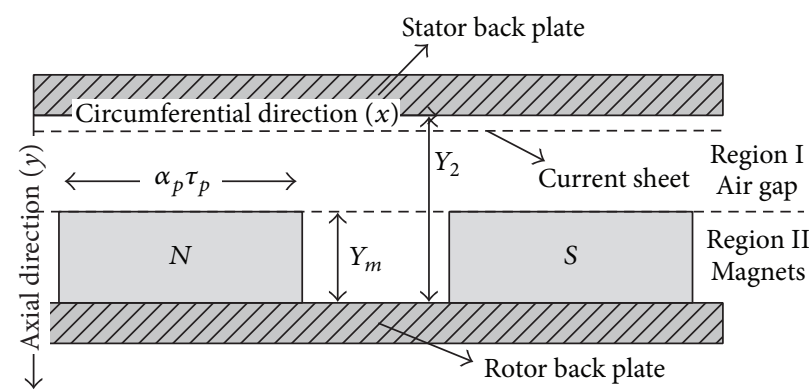

(a)

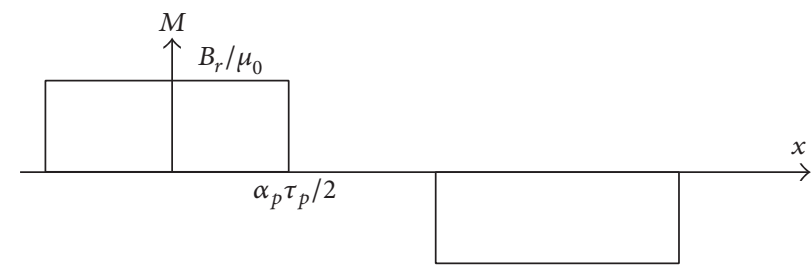

(b)

FIGURE 5: The model assuming infinitely permeable half planes with a smooth surface.

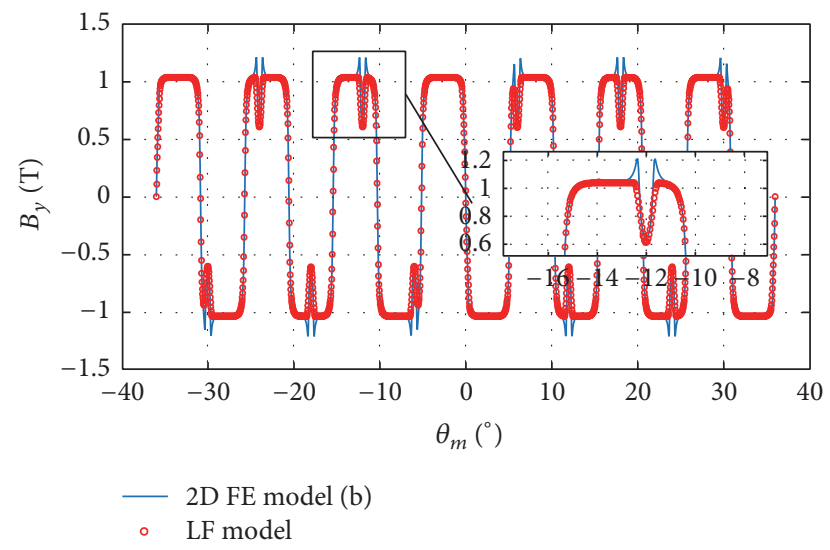

FIGURE 6: The axial flux density for $5 \mathrm{~mm}$ slot opening: comparison between the LF model and the 2D FE model.

where $U_{n}=n \pi / \tau_{p}$, and $\Delta$ is calculated as in

$$
\begin{aligned}
\Delta= & \mu_{r} \cosh \left(U_{n_{i}} Y_{m}\right) \sinh \left(U_{n_{i}}\left(Y_{2}-Y_{m}\right)\right) \\
& +\cosh \left(U_{n_{i}}\left(Y_{2}-Y_{m}\right)\right) \sinh \left(U_{n_{i}} Y_{m}\right),
\end{aligned}
$$

In a second step, the effect of the slot opening is included using a simple conformal mapping technique described in [11]. This technique introduces a permeance function $\lambda_{\mathrm{LF}_{i}}(x, y)$ which can be multiplied with the axial flux density in (5), resulting in the total axial flux density $B_{y_{\mathrm{LF}_{i}}}$ for slice number $i$.

$$
B_{y_{\mathrm{LF}_{i}}}(x, y)=B_{y I_{i}}(x, y) \lambda_{\mathrm{LF}_{i}}(x, y) .
$$

The axial flux density for this method is shown in Figure 6. It shows that the predicted axial flux density using this method is comparable to the $2 \mathrm{D}$ FE model. The horizontal axis in Figure $6\left(\theta_{m}=x / R_{\text {av }}^{i}\right)$ represents the circumferential angle in degrees.

The force is now computed by assuming that the flux density computed by (7) is circular near the slot opening, as shown in Figure 7. Figure 7 divides the slot opening regions in two parts. One part results in a positive force, while the other part results in a negative one. The radius of the flux path is $r_{\mathrm{so}}$.

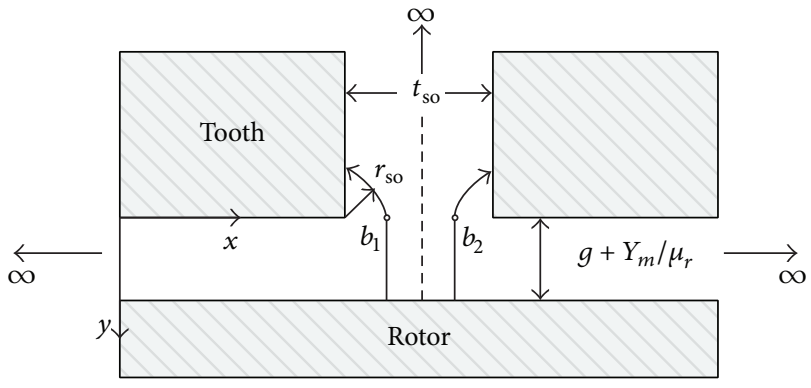

FIgURE 7: The cogging torque model using LF model [22].

The actual torque computation is done by integrating along the entire flux path under half of the slot opening [22].

$$
T_{c}=\sum_{i=1}^{N_{s}} t_{\mathrm{cp}} \int_{0}^{t_{\mathrm{so}} / 2} \frac{\left(B_{y_{\mathrm{LF}_{\mathrm{b}_{2} i}}^{2}}^{2}-B_{y_{\mathrm{LF}_{\mathrm{bl}_{1}}}}^{2}\right)}{\left(2 \mu_{0}\right)} R_{\mathrm{av}}^{i} d r_{\mathrm{so}},
$$

where $B_{y_{\mathrm{LF}_{\mathrm{bl}_{1}}}}(x, y)$ is the flux density beneath the slot opening at the left side of Figure 7, while $B_{y_{\mathrm{LF}_{b_{2}}}}(x, y)$ is the flux density on the right side of Figure 7 and $t_{\mathrm{so}}$ is the slot opening width. The flux density is computed using (7).

The LF method can only compute the cogging torque because it neglects the energy variations in the part of the air gap that does not lie below the slot opening. Therefore, it is not used for the calculation of the total torque.

\subsection{Conformal Mapping Using Complex Schwarz Christoffel} Transformation (SC Model). SC models use a conformal mapping technique, introduced by Žarko et al. in [12], to account for the slotting effect. This technique transforms the complex shapes of the slots into a smooth surface as shown in Figure 8. The transformation is done in two steps. The complex plane ( $Z$-plane) is first transformed to the so-called mid plane ( $W$-plane), which is then transformed to a smooth surface ( $T$-plane). The equations of these transformations can be found in [13].

In the T-plane, (4) and (5) are again valid for the noload situation. The armature-reaction field is calculated by introducing a current sheet, shown in Figure 5. The equations 


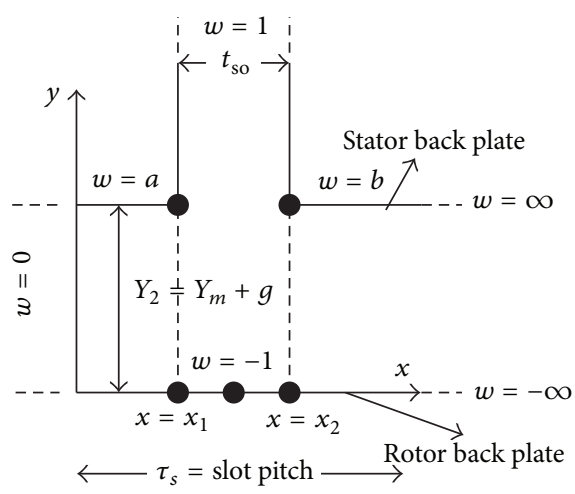

(a) Z-plane, $z=y+j x$

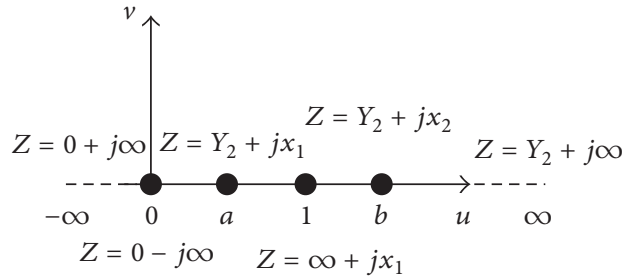

(b) $W$-plane, $w=u+j v$

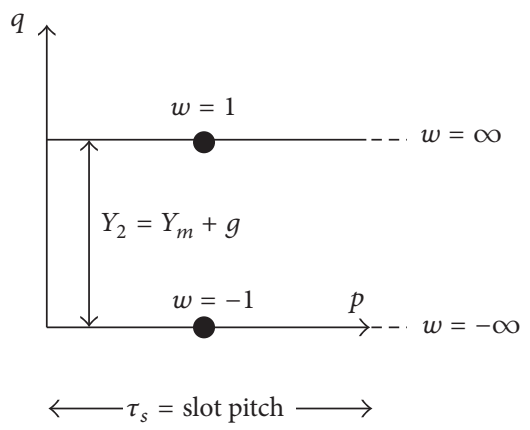

(c) $T$-plane, $t=q+j p$

Figure 8: The slot transformation from a complex plane ( $Z$-plane) to a smooth surface ( $T$-plane) [13].

for the flux densities resulting from this current sheet are described in [13].

The inverse transformations (from the $T$-plane back to the $Z$-plane) result in a complex permeance function $\lambda_{\mathrm{SC}_{i}}(x$, $y$ ), which is discussed in more detail in [13].

The conjugate of $\lambda_{\mathrm{SC}_{i}}(x, y)$ denoted by $\lambda_{\mathrm{SC}_{i}}(x, y)^{*}$ is multiplied with the $x$ and $y$ components of the flux assuming a smooth surface to obtain the total axial $B_{y_{\mathrm{SC}_{i}}}(x, y)$ and circumferential $B_{x_{\mathrm{SC}_{i}}}(x, y)$ flux density, including the slotting effect.

$$
\begin{aligned}
& B_{y_{\mathrm{SC}_{i}}}(x, y)+j B_{x_{\mathrm{SC}_{i}}}(x, y) \\
& \quad=\left(B_{y I_{i}}(x, y)+j B_{x I_{i}}(x, y)\right) \lambda_{\mathrm{SC}_{i}}(x, y)^{*} .
\end{aligned}
$$

The torque is calculated afterwards using the Maxwell stress tensor [13].

$$
T_{c}=\frac{1}{\mu_{0}} \sum_{i=1,2, \ldots}^{N_{s}} \int_{0}^{2 \pi R_{\mathrm{av}}^{i}} R_{\mathrm{av}}^{i} B_{x_{\mathrm{SC}_{i}}}(x, y) B_{y_{\mathrm{SC}_{i}}}(x, y) t_{\mathrm{cp}} d x
$$

The comparison of the axial flux density $B_{y_{\mathrm{SC}}}$ and the circumferential flux density $B_{x_{S C}}$ with the $2 \mathrm{D} \mathrm{FE}$ model (a) is shown in Figures 9 and 10, respectively. The comparison is done for a slot opening of $5 \mathrm{~mm}$. Figure 9 shows that the axial flux density is in good agreement with the 2D FE model. Comparing Figure 9 and Figure 6 shows that the SC model is more accurate than the LF model.

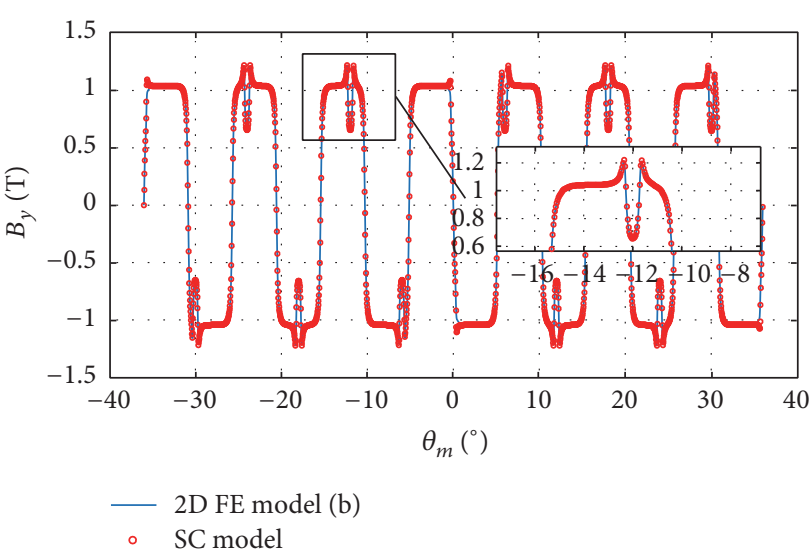

FIgure 9: Axial flux density component $B_{y}$ of the SC model compared with the 2D FE model at no load.

However, at a time instant of zero, the correspondence in Figure 10 shows that the $x$-component of the field does not correspond to the 2D FE model. This results in an error in the calculation of the cogging torque as will be shown later. The deviation between the 2D FE model and the analytical models is discussed in more detail in Section 4.2.

Figures 11 and 12 show the axial and circumferential flux densities under armature-reaction conditions. The currents are injected into the current sheets taking into account the 


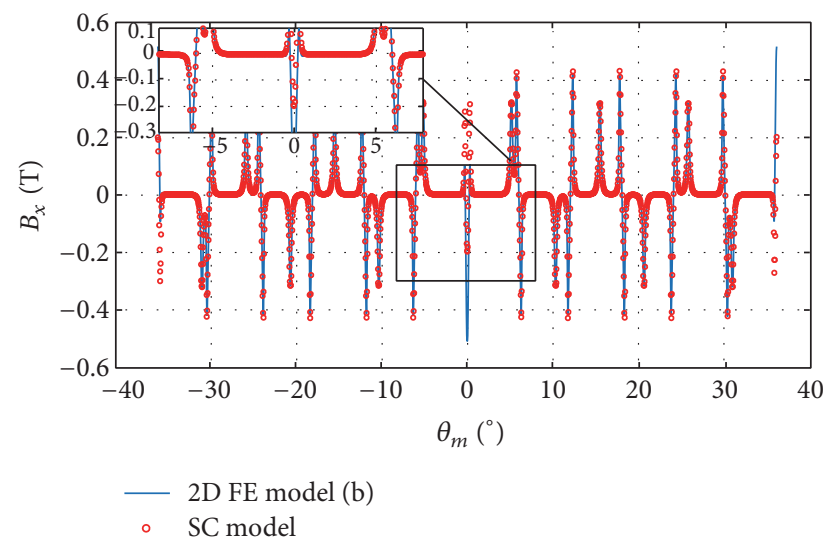

Figure 10: Circumferential flux density component $B_{x}$ of the SC model compared with the 2D FE model at no load.

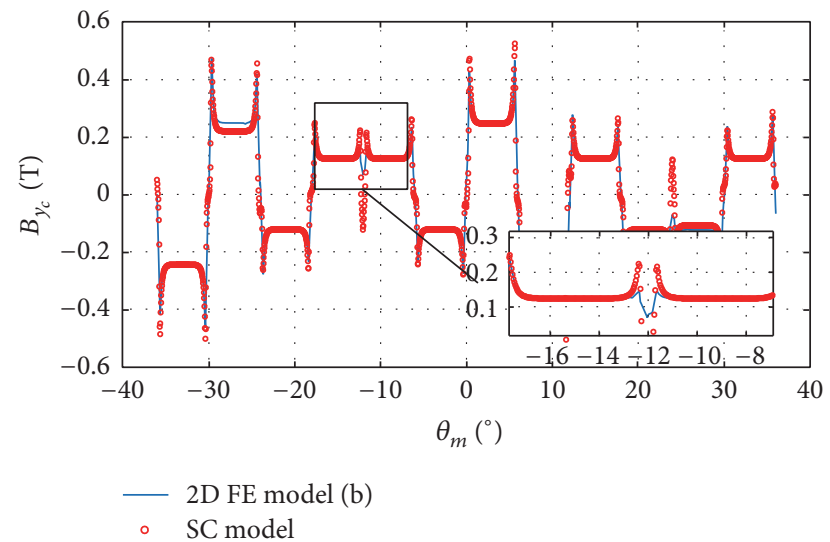

FIgURE 11: Axial flux density component $B_{y}$ of the SC model compared with the 2D FE model considering only armature current.

slotting effect. It is clear that there is a small error between the analytical and the FE model.

It is true that the surface becomes smooth when transforming from the $Z$-plane to the $T$-plane and the calculation of the flux density is much easier in the $T$-plane. However, the transformation introduces a deformation of the PM, causing errors in the calculation of the flux densities which, in turn, lead to a major error in the calculation of cogging torque and the torque ripple [13].

3.3. Subdomain Model (SD Model). In the SD model, the slots are assumed to be infinitely deep, as shown in Figure 13. In this model, the interdependence of different slots is considered.

The machine's geometry, consisting of $N_{s}$ slots and $N_{m}$ PMs, is divided into three main regions.

(1) Region $\left(I_{k}\right)$ : the slotting region consists of several subdomains $\left(1,2, \ldots, k, \ldots, N_{s}\right)$, where the variable $k$ indicates the number of the slot. The current $I_{k}$ with a current density $J_{k}$ is imposed to each slot, as shown in Figure 13. In this region, the periodicity of the solution

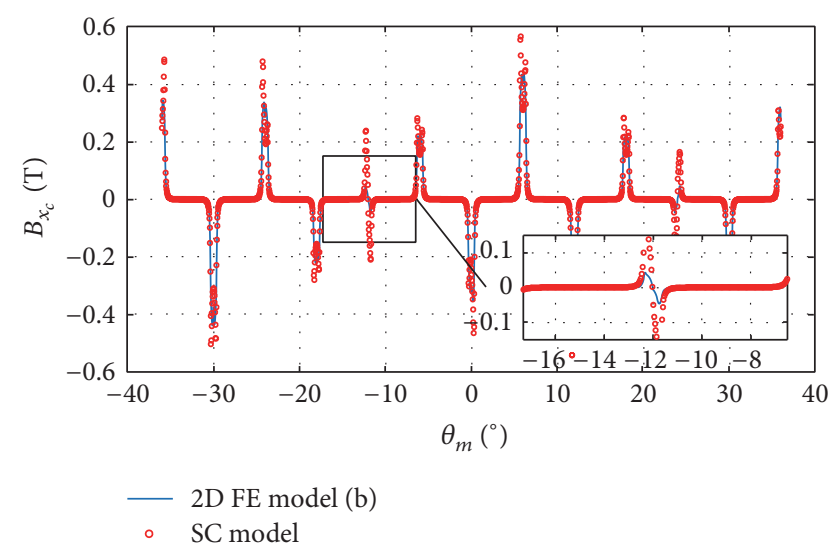

FIGURE 12: Circumferential flux density component $B_{x}$ of the SC model compared with the 2D FE model considering only armature current.

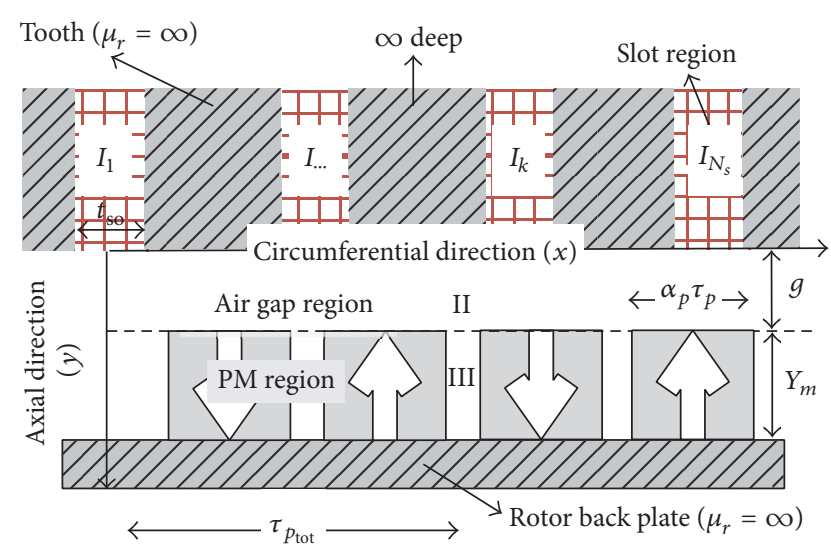

Figure 13: The subdomain model.

$\left(W_{s}\right)$ is determined by the width of the slot opening $\left(t_{\mathrm{so}}\right)$.

$$
W_{s}=\frac{s \pi}{t_{\text {so }}}, \quad s=1,2,3, \ldots, \infty,
$$

where $s$ represents the harmonic orders in the slot region.

(2) Region (II): this region covers the air gap area.

(3) Region (III): this region contains the PMs.

In regions (II) and (III), the periodicity is defined by the pole pitch multiplied with the number of pole pairs of the machine divided by the number of symmetries in the machine $(z)$.

$$
z=\operatorname{gcd}\left(N_{s}, p\right),
$$

where $p=N_{m} / 2$ is the number of pole pairs and gcd is the greatest common divisor.

The periodicity in these regions equals

$$
\tau_{p_{\text {toti }}}=\frac{p \tau_{p_{i}}}{z}
$$


where $\tau_{p_{i}}=2 \pi R_{\mathrm{av}_{i}} / N_{m}$ is the pole pitch at slice $i$. The periodicity of this region is determined by

$$
W_{m}=\frac{m \pi}{\tau_{\text {ptoti }_{i}}}, \quad m=1,2,3, \ldots, \infty,
$$

where $m$ represents the harmonics in the air gap and PM region.

Using the magnetic vector potential $(\vec{A})$, Maxwell's equations can be rewritten in the form of a second-order differential equation in each of the subdomains.

$$
\begin{aligned}
& \nabla^{2} \overrightarrow{A_{I_{k}}}=0, \text { Region } I_{k} \\
& \nabla^{2} \overrightarrow{A_{\text {II }}}=0 \text {, Region II } \\
& \nabla^{2} \overrightarrow{A_{\text {III }}}=-\mu_{0}(\nabla \times \vec{M}), \text { Region III, }
\end{aligned}
$$

resulting in the following equation for the magnetic vector potential for each region:

$$
\begin{aligned}
& A_{z I_{k}}=\sum_{s=1,2, \ldots}^{\infty} \frac{1}{W_{s}}\left[\left(A_{I_{k}} e^{W_{s} y}+B_{I_{k}} e^{-W_{s} y}\right) \cos \left(W_{s} x\right)\right. \\
& \left.+\left(C_{I_{k}} e^{W_{s} y}+D_{I_{k}} e^{-W_{s} y}\right) \sin \left(W_{s} x\right)\right]-\mu_{0} J_{k}, \\
& A_{z \mathrm{II}}=\sum_{m=1,2, \ldots}^{\infty} \frac{1}{W_{m}}\left[\left(A_{\mathrm{II}} e^{W_{m} y}+B_{\mathrm{II}} e^{-W_{m} y}\right) \cos \left(W_{m} x\right)\right. \\
& \left.\quad+\left(C_{\mathrm{II}} e^{W_{m} y}+D_{\mathrm{II}} e^{-W_{m} y}\right) \sin \left(W_{m} x\right)\right], \\
& A_{z \mathrm{III}} \\
& \quad=\sum_{m=1,2, \ldots .}^{\infty} \frac{1}{W_{m}}\left[\left(A_{\mathrm{III}} e^{W_{m} y}+B_{\mathrm{III}} e^{-W_{m} y}\right) \cos \left(W_{m} x\right)\right. \\
& \left.\quad+\left(C_{\mathrm{III}} e^{W_{m} y}+D_{\mathrm{III}} e^{-W_{m} y}\right) \sin \left(W_{m} x\right)\right] .
\end{aligned}
$$
by

The flux densities at slice number $i$ can now be obtained

$$
\begin{aligned}
& B_{y_{\mathrm{SD}_{i}}}=-\frac{\partial A_{z}}{\partial x}, \\
& B_{x_{\mathrm{SD}_{i}}}=\frac{\partial A_{z}}{\partial y} .
\end{aligned}
$$

The integration constants, introduced in the solutions of the different subdomains (16), are then defined by imposing conditions on the subdomains' boundaries. A more detailed discussion on the SD technique, including the boundaries and the final solution can be found in [19].

The comparisons of the no-load axial and circumferential flux densities, that is, $B_{y}$ and $B_{x}$, with the results from the $2 \mathrm{D}$ FE model are shown in Figures 14 and 15, respectively. The flux densities are compared with the 2D FE model shown in Figure 3(a) with the tooth tips included at a slot opening of $5 \mathrm{~mm}$. It clearly shows that the correspondence is very good.

Figures 16 and 17 show the axial and tangential flux density, respectively, of the armature-reaction field. They show good correspondence with the 2D FE model.

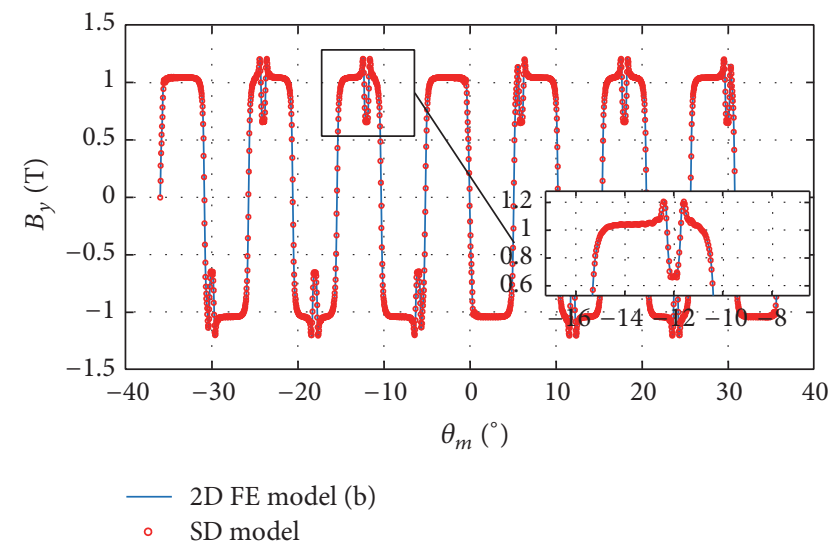

FIgURE 14: Axial flux density component $B_{y}$ of the SD model compared with the 2D FE model at no load.

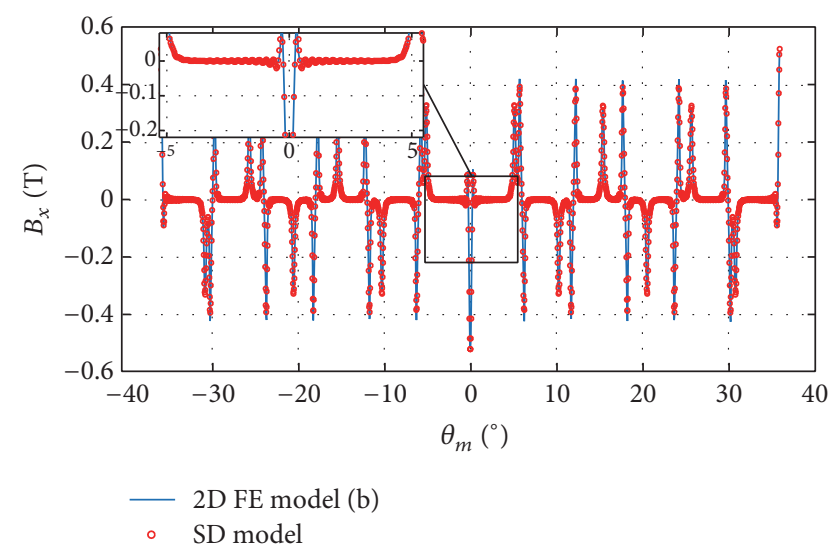

FIgURE 15: Circumferential flux density component $B_{x}$ of the SD model compared with the 2D FE model at no load.

\section{Comparison between Different Models}

4.1. Comparison of CPU Time. Table 2 summarizes the CPU time for each of the tested models. All calculations were done on a PC operating a 64-bit version of Windows 7; the PC has a core i7 processor and a memory of $8 \mathrm{~GB}$. Both 2D FE and analytical models divide the machine into eight slices. All models were computed for 50 positions of the rotor, equally divided over one cycle. The comparison shows that the $3 \mathrm{D}$ FE model is very time consuming compared to the other models. In addition, both 2D FE models required one hour of computation which is still very time consuming. The comparison also shows the superiority of analytical models compared to the FE models. Moreover, the LF and the SC models are much faster than the SD model, this is due to the more complex equations that have to be solved in the SD model. The LF and SC models use 300 harmonic orders for the calculation of the PM flux density, while the SD model uses 280 in the air gap and PM area and 35 harmonics in each slot.

4.2. Comparison of Flux Densities. Tables 3 and 4 show the second vector norm of the error between the circumferential 


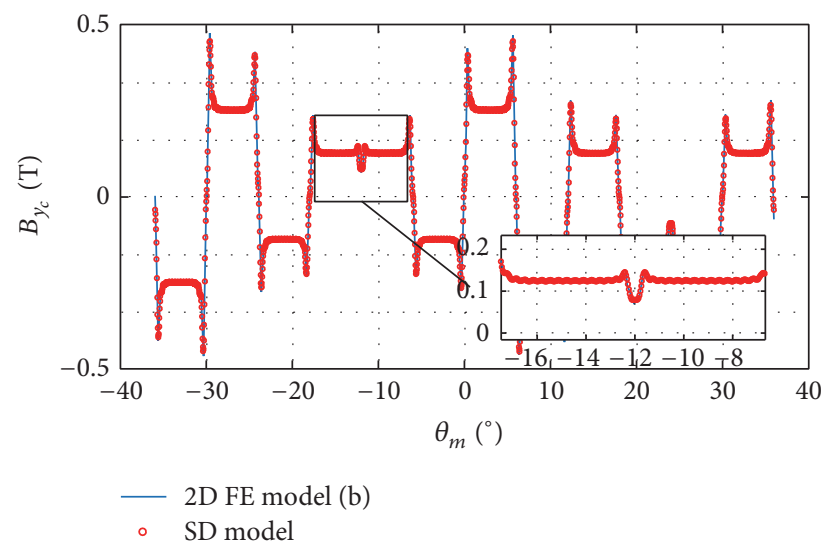

FIgUre 16: Axial flux density component $B_{y}$ of the SD model compared with the 2D FE model considering only armature current.

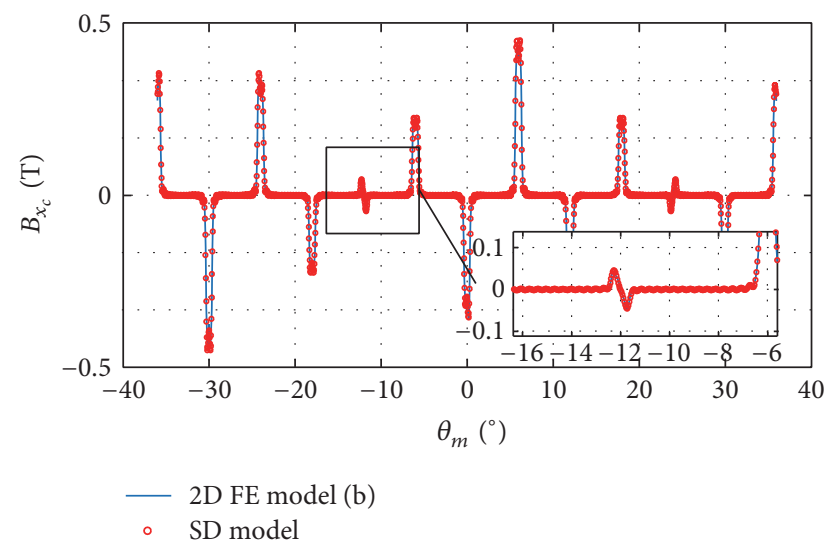

FIGURE 17: Circumferential flux density component $B_{x}$ of the SD model compared with the 2D FE model considering only armature current.

TABLE 2: Comparison of the CPU time between the analytical and the FE models.

\begin{tabular}{lc}
\hline Model type & CPU time \\
\hline FE models & \\
3D FE model & $10 \mathrm{hrs}$ \\
2D FE model (a) & $1 \mathrm{hr}$ \\
2D FE model (b) & $1 \mathrm{hr}$ \\
Analytical models & \\
LF model & $13 \mathrm{~s}$ \\
SC model & $15 \mathrm{~s}$ \\
SD model & $40 \mathrm{~s}$ \\
\hline
\end{tabular}

( $x$ ) and axial $(y)$ flux densities of the different analytical models and the 2D FE model shown in Figure 3(a). Table 3 shows the error for no-load condition and Table 4 shows it for armature-reaction conditions. It can be seen that the SD model is the most accurate model in all circumstances. In addition, the SC model is more accurate than the LF model for the calculation of the axial component. The norm of the error in the circumferential flux density for the SC model is very high compared to the SD model.
TABLE 3: Comparison of the no-load flux density between the analytical and the 2D FE models.

\begin{tabular}{lcc}
\hline Analytical model type & $\left\|\left(B_{y_{\text {ana }}}-B_{y_{\mathrm{FE}}}\right)\right\|_{2}$ & $\left\|\left(B_{x_{\mathrm{ana}}}-B_{x_{\mathrm{FE}}}\right)\right\|_{2}$ \\
\hline LF model & 2.3 & - \\
SC model & 0.9 & 1.6 \\
SD model & 0.5 & 0.45 \\
\hline
\end{tabular}

TABle 4: Comparison of the full load flux density between the analytical and the 2D FE models considering only armature current.

\begin{tabular}{lcc}
\hline Analytical model type & $\left\|\left(B_{y_{\text {ana }}}-B_{y_{\mathrm{FE}}}\right)\right\|_{2}$ & $\left\|\left(B_{x_{\mathrm{ana}}}-B_{x_{\mathrm{FE}}}\right)\right\|_{2}$ \\
\hline SC model & 1.2 & 1.36 \\
SD model & 0.24 & 0.24 \\
\hline
\end{tabular}

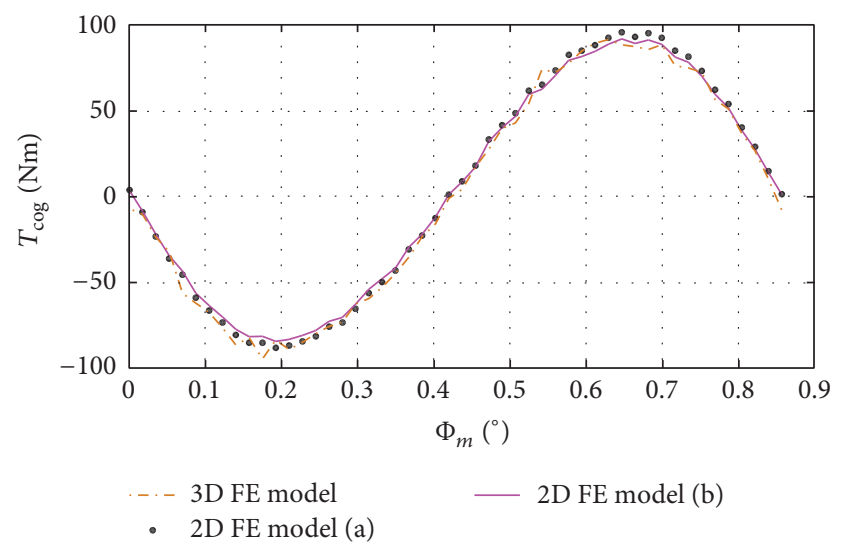

FIGURE 18: Cogging torque variations for different rotor positions $\Phi_{m}$ for the three FE models only.

4.3. Comparison of Cogging Torque. Figure 18 shows the difference between the three FE models described in the paper for cogging torque computation at $5 \mathrm{~mm}$ slot opening. The horizontal axis in Figure 18 indicates the rotor's position $\left(\Phi_{m}\right)$. Figure 18 shows that the 2D FE models may indeed be used as reference solution. Their deviation with regard to the $3 \mathrm{D}$ FE model is negligible. Figure 18 also confirms that the usage of the geometry without tooth tips is sufficient to describe the cogging torque for all other geometries.

The cogging torque for the analytical models and the FE model without tooth tips is shown in Figure 19. It is clear that the subdomain model is the most accurate one. It is clear also that the models based on lateral force (LF) and complex Schwarz Christoffel (SC) models can not accurately predict the cogging torque.

Figure 20 depicts the peak-to-peak value of the cogging torque as a function of the slot opening. The PM is a rectangular shape of $40 \mathrm{~mm}$ width. The $x$-axis in this figure indicates the slot opening over the tooth pitch at minimum radius. It is obvious that at a certain slot opening, the cogging torque is minimized. The SD model is the most accurate analytical tool to predict both the value of the cogging torque and the locus of minimum cogging torque. The models based 


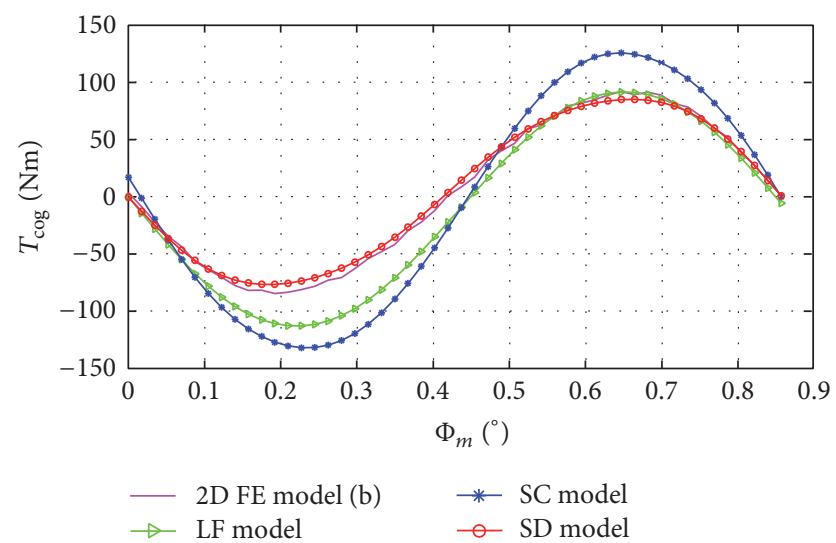

FIGURE 19: Cogging torque variations for different rotor positions $\Phi_{m}$ for the FE model (b) and the analytical models.

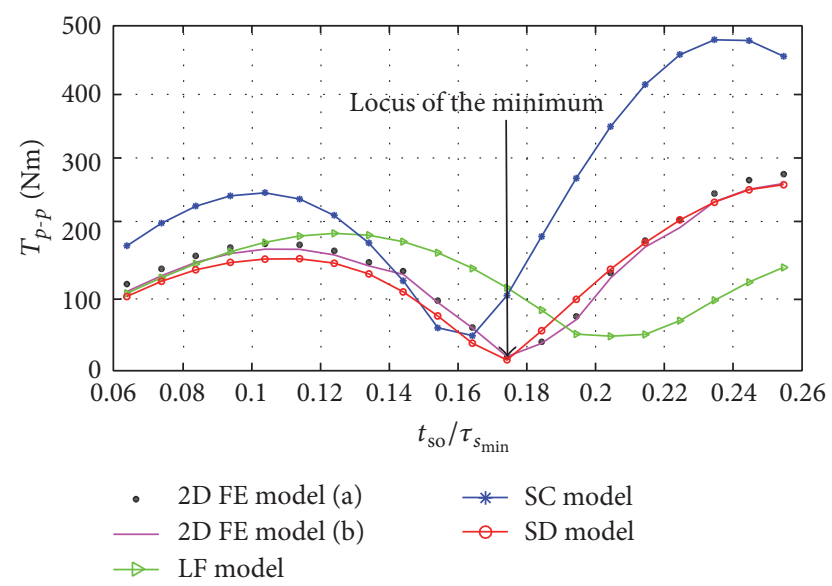

FIGURE 20: Impact of slot opening on the peak-to-peak cogging torque.

on LF and SC cannot exactly determine the value of the cogging torque nor the locus of the minimal cogging torque.

Figure 21 describes the variations of the peak-to-peak cogging torque with respect to the ratio between $\mathrm{PM}$ width and pole arc at minimum radius. A similar observation can be noticed. In this figure, the most accurate model is the SD one. In addition, the SC model succeeded to obtain the locus of minimum cogging torque. However, it could not obtain the same peak-to-peak value as the 2D FE model.

4.4. Comparison of Torque Ripple at Full Load. The torque waveform at full load is studied in Figure 22. It shows that the $2 \mathrm{D}$ FE model can accurately predict the mean value of torque and torque ripple, giving almost the same results as the $3 \mathrm{D}$ FE model. Both versions of the 2D FE models can accurately predict the torque and its ripple. However, the SD model resulted in a less accurate solution compared to the $3 \mathrm{D}$ FE models. The error occurs because the FE model calculates the torque using the magnetic coenergy while the analytical models calculate it using Maxwell stress tensor. The SD model can track the results in comparison with the 2D FE model (b) without tooth tips. Moreover, the SD model can predict

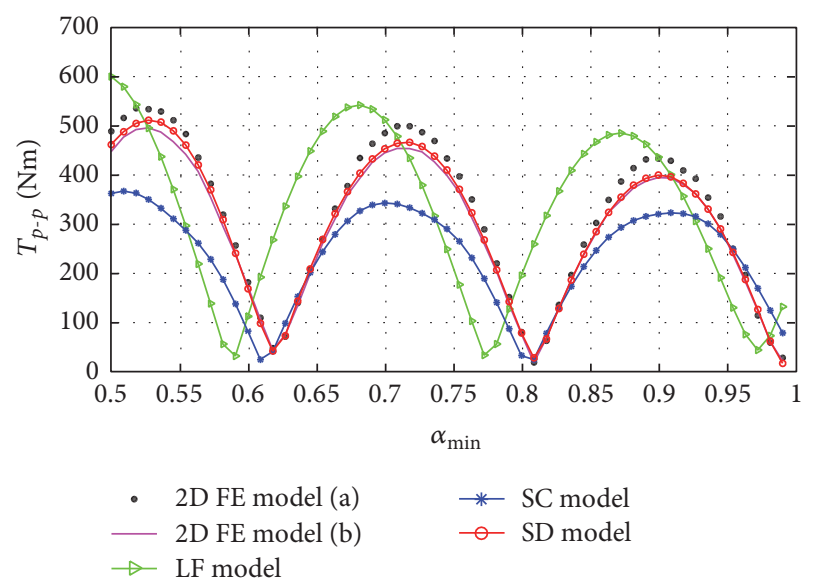

FIGURE 21: Impact of pole arc to pole pitch ratio at minimum radius on the peak-to-peak cogging torque.

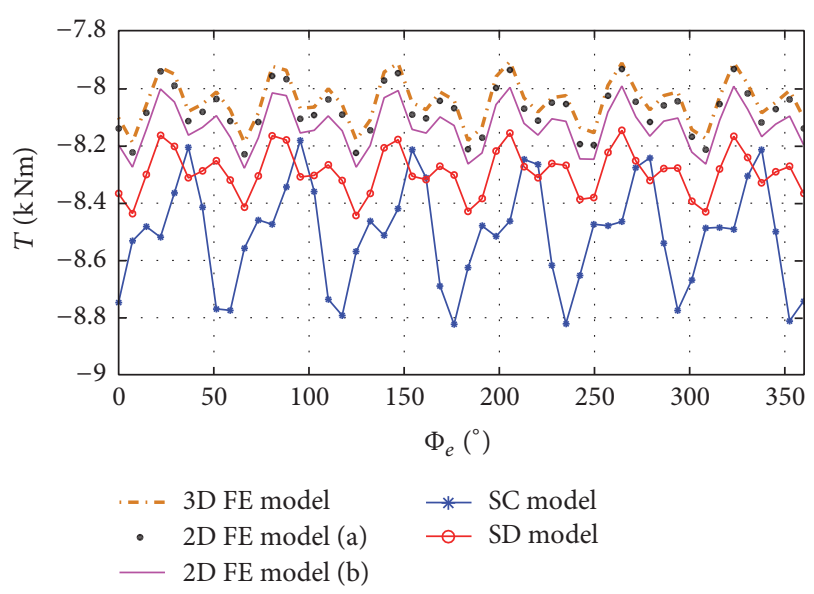

FIGURE 22: Electromagnetic torque variations output for different models with respect to the electrical angle $\Phi_{e}$.

almost the same value of torque ripple. The SC model is less accurate for the calculation of torque ripple and mean value of torque.

Table 5 summarizes the results. It shows the mean torque values for each method and the error relative to the mean torque of the $3 \mathrm{D}$ FE models. It also shows the peak-to-peak torque error relative to the peak-to-peak torque of the $3 \mathrm{D} \mathrm{FE}$ model. It clearly states that the SC model cannot accurately predict the torque ripple. It can predict the mean value of torque with a $6 \%$ error. In addition, the SD model is robust enough to predict both the torque ripple and the mean torque. It clearly states that both $2 \mathrm{D}$ FE models can predict the torque ripple and mean torque accurately.

4.5. Effect of Number of Slices on Cogging Torque and Torque Ripple. From the above discussions, it is clear that the subdomain model can accurately describe the cogging torque of the machine. However, the number of slices is an important criterion in determining the accuracy of the prediction of the cogging torque. Therefore, a comparison is done, in Figures 23 and 24, between the 3D FE model and the subdomain 
TABLE 5: Comparison of the mean torque, torque ripple, and relative error compared to the 3D FE model.

\begin{tabular}{|c|c|c|c|c|c|}
\hline & \multicolumn{5}{|c|}{ Model type } \\
\hline & \multicolumn{3}{|c|}{ FE models } & \multicolumn{2}{|c|}{ Analytical models } \\
\hline & 3D FE model & 2D FE model (a) & 2D FE model (b) & SC model & SD model \\
\hline$T_{\text {mean }}(\mathrm{kNm})$ & -8.04 & -8.07 & -8.13 & -8.5 & -8.3 \\
\hline Error $_{T_{m}}(\%)$ & 0 & 0.4 & 1 & 6 & 3 \\
\hline$T_{p-p}(\mathrm{Nm})$ & 282 & 297 & 286 & 642 & 297 \\
\hline Error $_{T_{r}}(\%)$ & 0 & 5 & 1.5 & 128 & 5 \\
\hline
\end{tabular}

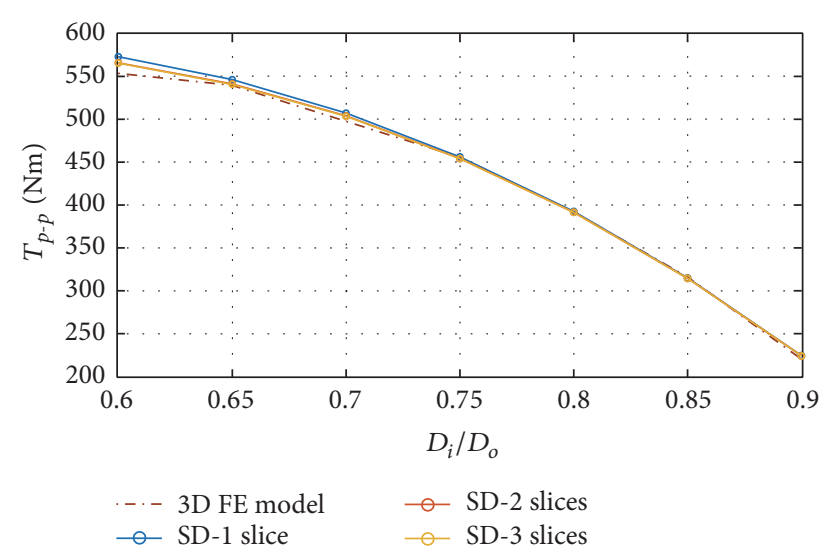

FIGURE 23: Peak-to-peak cogging torque for different inner to outer diameter ratio $D_{i} / D_{o}$ between the 3D FE model and the subdomain model for different numbers of slices for trapezoidal PM.

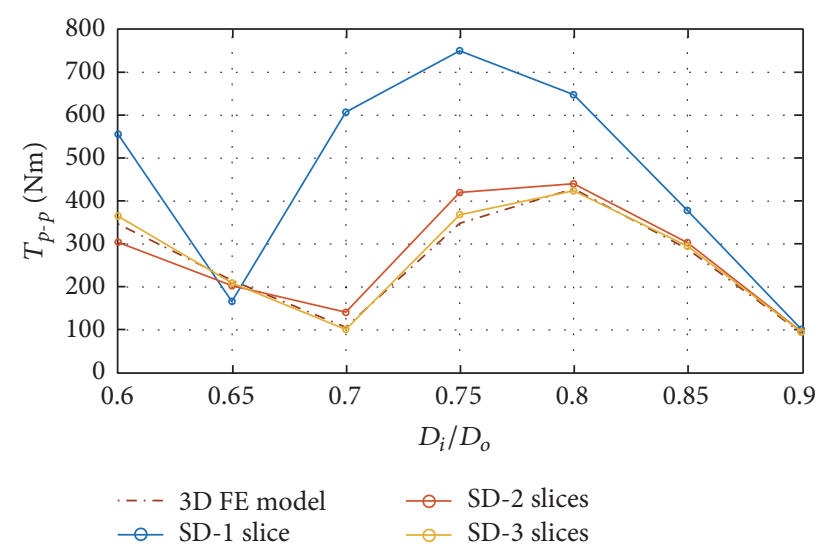

FIGURE 24: Peak-to-peak cogging torque for different inner to outer diameter ratio $D_{i} / D_{o}$ between the $3 \mathrm{D} \mathrm{FE}$ model and the subdomain model for different numbers of slices for rectangular PM.

model for different numbers of slices with respect to the inner to outer diameter $\left(D_{i} / D_{o}\right)$. This is done for two different types of PMs, trapezoidal and rectangular PMs shapes shown in Figures 25(a) and 25(b), respectively. It is clear that, for trapezoidal PM, the minimum number of slices to sufficiently describe the cogging torque amplitude is two slices. However, the minimum number of slices for rectangular PM is three. This test is done for a slot opening of $5 \mathrm{~mm}$ and a pole arc ratio of 0.9 for the trapezoidal $\mathrm{PM}$ and 0.9 at the minimum radius for the rectangular PM.

The cogging torque is generated because of the interaction between the edges of the slot opening and the edges of the PMs. The relative distance for trapezoidal PM shape does not change over the radial direction of the machine. Therefore, one slice would be sufficient to describe the cogging torque behaviour. However, to increase the accuracy, the authors prefer two slices. For rectangular shaped PM, the relative distance does change over the radial direction. Therefore, for more accurate results, three slices would be sufficient.

Figures 26, 27, and 28 show the cogging torque variations for trapezoidal, rectangular, and T-type PM, respectively. Figure 26 depicts the notion that two slices are enough for the representation of cogging torque. Additional slices result in more computation time without extra accuracy. For rectangle PM, shown in Figure 27, three slices are enough. For T-type $\mathrm{PM}$, a minimum of 6 slices would be sufficient to describe the cogging torque.

To study the effect of the number of slices on the torque ripple, Figure 29 compares the 3D FE model with the subdomain model with various number of slices for rectangular shaped PM $\left(n_{s}\right)$. It is clear that for three slices the peak-topeak ripple torque converges and additional slices do not offer additional accuracy.

\section{Experimental Validation}

The SC and SD models are compared with the test setup shown in Figure 30 [5]. The induction machine shown in Figure 30 is driving the AFPMSM at a constant speed. The AFPMSM is loaded with a resistive load. The data of the AFPMSM is shown in Table 6.

Figure 31 compares the no-load voltage of the experimental setup at $2000 \mathrm{rpm}$ with the SC model and the SD model. It clearly shows that there is no noticeable difference between the no-load voltage of the experimental setup and the two models. The no-load voltage is mostly dependent on the axial flux density shown in Figures 9 and 14, for the SC and SD models, respectively. These figures show good agreement with the 2D FE model. The rms no-load voltages are $127 \mathrm{~V}$, $137 \mathrm{~V}$, and $135 \mathrm{~V}$ for the experimental setup, SC model, and SD model, respectively.

Figure 32 compares the full load torque of the experimental setup with the SC and SD models. It is clear that the average torque is quite similar. The torque ripple for the SC and $\mathrm{SD}$ has a period of six times the fundamental frequency 


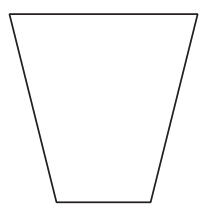

(a) Trapezoidal PM

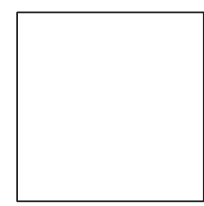

(b) Rectangular PM

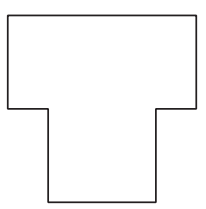

(c) T-shape PM

FIGURE 25: PM shapes used for the study of different slices.

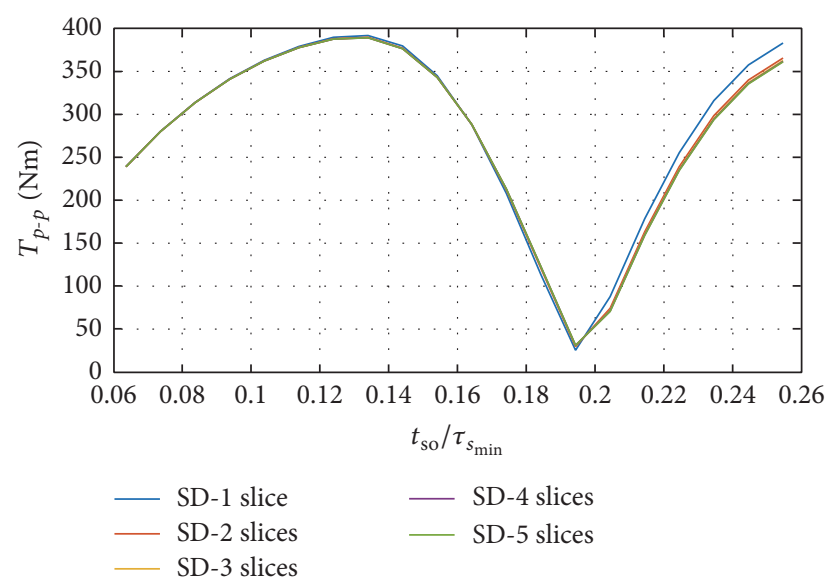

FIGURE 26: Peak-to-peak cogging torque for different slot opening $t_{\text {so }}$ for the subdomain model for different numbers of slices for trapezoidal PM.

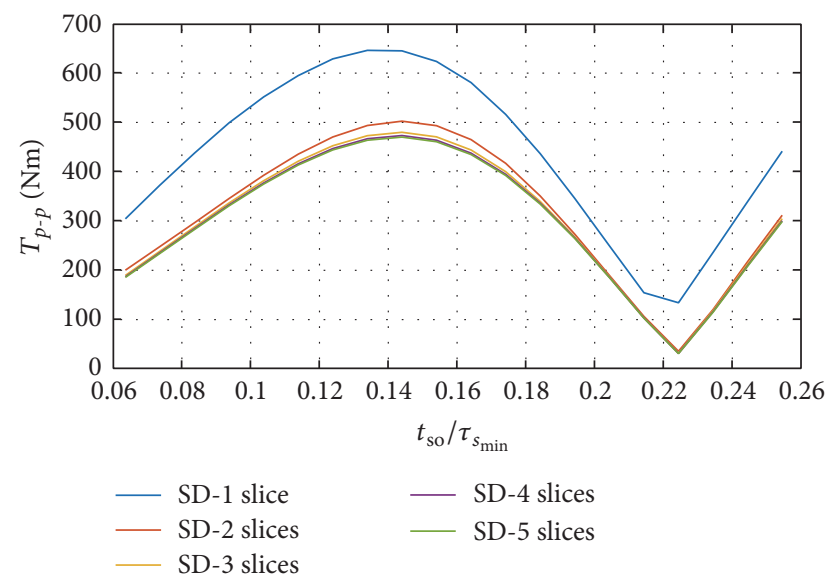

FIGURE 27: Peak-to-peak cogging torque for different slot opening $t_{\text {so }}$ for the subdomain model for different numbers of slices for rectangle $\mathrm{PM}$.

[4]. They are comparable with each other. The mean torque of the experimental test, SC model, and SD model is $14.9 \mathrm{Nm}$, $15 \mathrm{Nm}$, and $15 \mathrm{Nm}$. The torque is measured using a torque transducer shown in Figure 30 of Lorenz Messtechnik, DR2112-R. The torque can measure with a resolution of $0.1 \mathrm{Nm}$ and sufficient bandwidth to measure cogging torque.

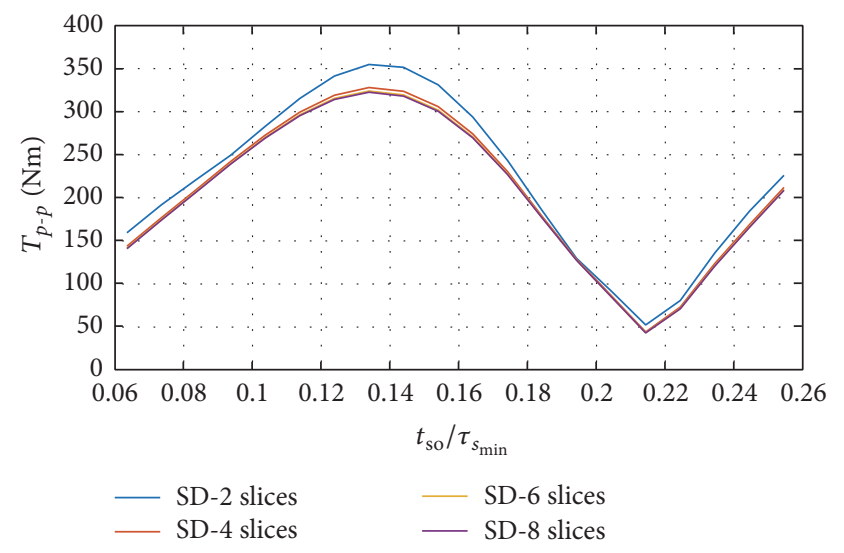

FIGURE 28: Peak-to-peak cogging torque for different slot opening $t_{\text {so }}$ for the subdomain model for different numbers of slices for Ttype PM.

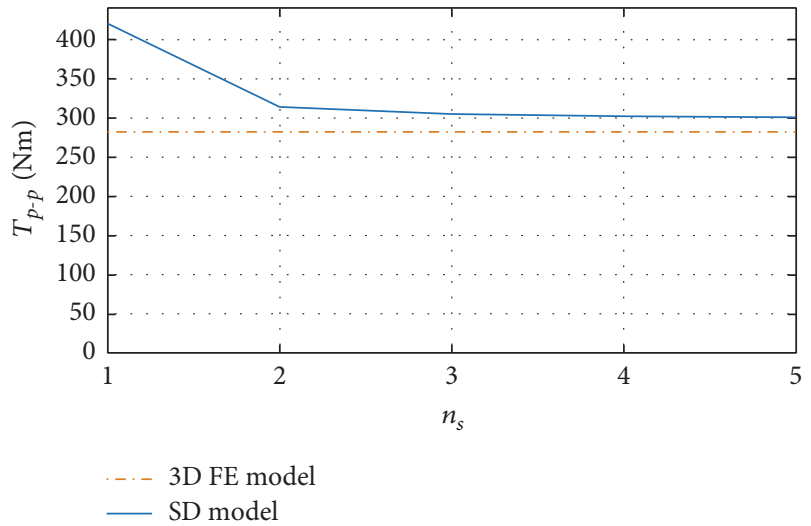

FIGURE 29: Peak-to-peak ripple torque comparison between the 3D $\mathrm{FE}$ and the subdomain model for different numbers of slices for rectangular shaped $\mathrm{PM}$.

\section{Conclusions}

This paper investigated the effect of different modeling techniques on the prediction of the cogging torque and torque ripple at full load. A comparison between a 3D FE model, 2D FE models, and the analytical models has been done. Two types of FE models are studied in this paper, that is, a model with and one without tooth tips. The $2 \mathrm{D}$ FE model without tooth tips is used as reference solution to compare the different analytical models. Three analytical 
TABLE 6: Experimental setup geometrical parameters [5].

\begin{tabular}{lcc}
\hline Parameter & Symbol & Value \\
\hline Rated power & $P_{n}$ & $4 \mathrm{~kW}$ \\
Number of pole pairs & $p$ & 8 \\
Number of stator slots & $N_{s}$ & 15 \\
Rated speed & $n_{r}$ & $2000 \mathrm{rpm}$ \\
Rated torque & $T_{\mathrm{em}}$ & $19.1 \mathrm{Nm}$ \\
Outer diameter & $D_{o}$ & $148 \mathrm{~mm}$ \\
Inner diameter & $D_{i}$ & $100 \mathrm{~mm}$ \\
Axial length core element & $Y_{s}+2\left(d_{1}+d_{2}\right)$ & $63 \mathrm{~mm}$ \\
Axial length slot & $Y_{s}$ & $48 \mathrm{~mm}$ \\
Slot width & $t_{s}$ & $13 \mathrm{~mm}$ \\
\hline
\end{tabular}

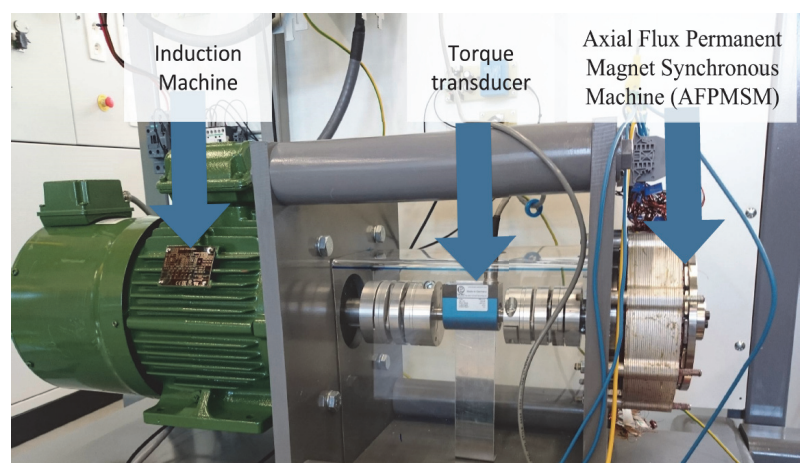

FIgURE 30: Experimental test setup [5].

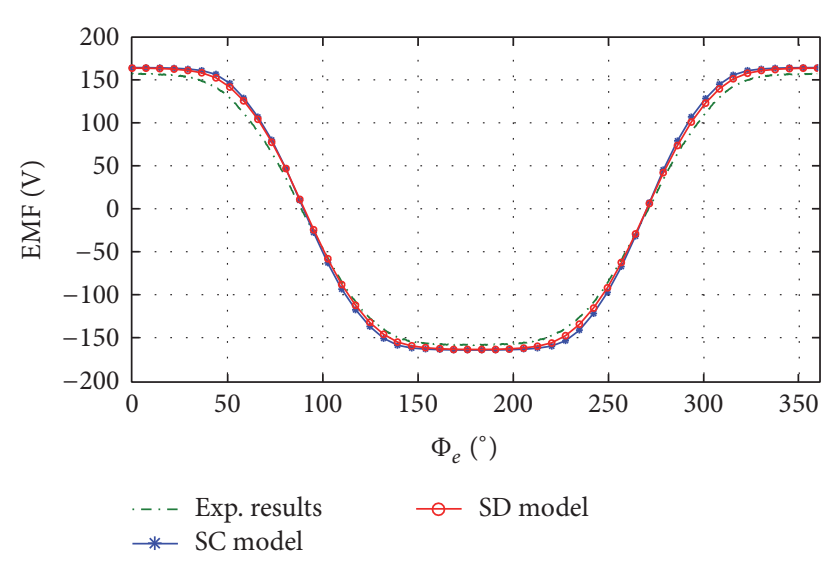

FIGURE 31: Comparison of the no-load voltage for different models with respect to the electrical angle $\Phi_{e}$.

models are studied in this comparison. One is based on the lateral force model using a simple Schwarz Christoffel transformation. Another model is based on a more complex Schwarz Christoffel transformation that can account for both axial and circumferential flux densities. The third model is based on the subdomain model (SD).

The comparison shows that both versions of the $2 \mathrm{D} F E$ models are capable of obtaining almost the same value for the cogging torque as the $3 \mathrm{D}$ model, which models the tooth tips.

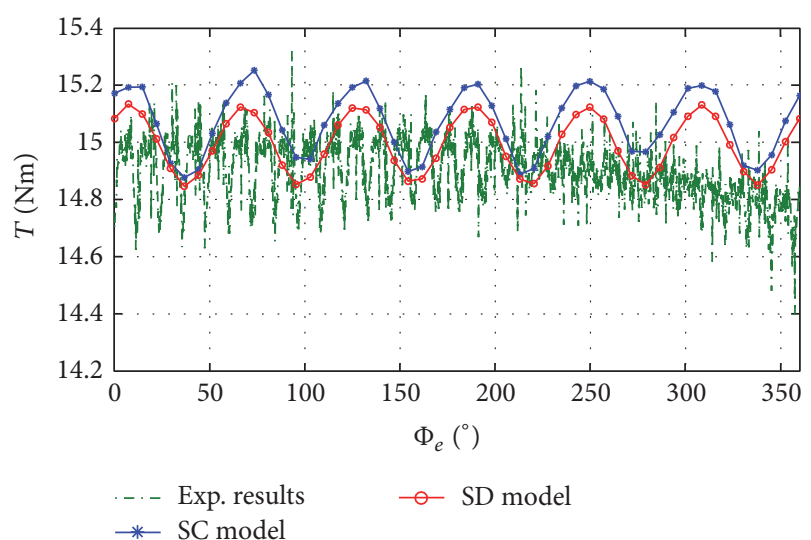

FIgURE 32: Comparison of the full load torque for different models with respect to the electrical angle $\Phi_{e}$.

This proves that neglecting the tooth tips results in a good solution for the cogging torque and torque ripple.

The comparison has clearly shown that the subdomain model is the only analytical model that can accurately compute the mean value of the torque and the torque ripple when compared to the 3D FE model.

Additional studies concerning slot opening variations and permanent-magnet pole arc width variations were done. They have clearly shown that the only method that is capable of obtaining the locus of minimum cogging torque and its value is the subdomain model. Therefore, it is well recommended for studies concerning optimization of cogging torque and torque ripple for the axial flux permanent-magnet synchronous machines to model the machine with this technique. The number of slices plays an important role in determining how accurate the subdomain model compared to the 3D FE model. Therefore, an optimum selection for the number of slices for the subdomain model is done to have an accurate solution for the cogging torque and torque ripple.

\section{Competing Interests}

The authors declare that they have no competing interests.

\section{Acknowledgments}

This work was supported by FWO Project G.0110.13.

\section{References}

[1] C. Du-Bar, Design of an axial flux machine for an in-wheel motor application [M.S. thesis], Chalmers Reproservice, Gothenburg, Sweden, 2011.

[2] M. Aydin and M. Gulec, "Reduction of cogging torque in double-rotor axial-flux permanent-magnet disk motors: a review of cost-effective magnet-skewing techniques with experimental verification," IEEE Transactions on Industrial Electronics, vol. 61, no. 9, pp. 5025-5034, 2014.

[3] P. Sergeant, H. Vansompel, and L. Dupré, "Influence of stator slot openings on losses and torque in axial flux permanent 
magnet machines," Mathematics and Computers in Simulation, vol. 130, pp. 22-31, 2016.

[4] M. Aydin, S. Huang, and T. A. Lipo, "Torque quality and comparison of internal and external rotor axial flux surface-magnet disc machines," IEEE Transactions on Industrial Electronics, vol. 53, no. 3, pp. 822-830, 2006.

[5] A. Hemeida, M. Taha, A. A. E. Abdallh, H. Vansompel, L. Dupre, and P. Sergeant, "Applicability of fractional slot axial flux permanent magnet synchronous machines in the field weakening region," IEEE Transactions on Energy Conversion, 2016.

[6] H. Tiegna, A. Bellara, Y. Amara, and G. Barakat, "Analytical modeling of the open-circuit magnetic field in axial flux permanent-magnet machines with semi-closed slots," IEEE Transactions on Magnetics, vol. 48, no. 3, pp. 1212-1226, 2012.

[7] H. Tiegna, Y. Amara, and G. Barakat, "A new quasi-3-D analytical model of axial flux permanent magnet machines," IEEE Transactions on Magnetics, vol. 50, no. 2, pp. 817-820, 2014.

[8] H. Tiegna, Y. Amara, and G. Barakat, "Study of cogging torque in axial flux permanent magnet machines using an analytical model," IEEE Transactions on Magnetics, vol. 50, no. 2, pp. 845848,2014

[9] H. Tiegna, Y. Amara, and G. Barakat, "Overview of analytical models of permanent magnet electrical machines for analysis and design purposes," Mathematics and Computers in Simulation, vol. 90, pp. 162-177, 2013.

[10] T. F. Chan, L. L. Lai, and S. Xie, "Field computation for an axial flux permanent-magnet synchronous generator," IEEE Transactions on Energy Conversion, vol. 24, no. 1, pp. 1-11, 2009.

[11] Z. Q. Zhu and D. Howe, "Instantaneous magnetic field distribution in brushless permanent magnet dc motors. Part III: effect of stator slotting," IEEE Transactions on Magnetics, vol. 29, no. 1, pp. 143-151, 1993.

[12] D. Žarko, D. Ban, and T. A. Lipo, "Analytical calculation of magnetic field distribution in the slotted air gap of a surface permanent-magnet motor using complex relative air-gap permeance," IEEE Transactions on Magnetics, vol. 42, no. 7, pp. 1828-1837, 2006.

[13] A. Hemeida and P. Sergeant, "Analytical modeling of surface PMSM using a combined solution of Maxwell-s equations and magnetic equivalent circuit," IEEE Transactions on Magnetics, vol. 50, no. 12, article 7027913, 2014.

[14] T. Lubin, S. Mezani, and A. Rezzoug, "2-D exact analytical model for surface-mounted permanent-magnet motors with semi-closed slots," IEEE Transactions on Magnetics, vol. 47, no. 2, pp. 479-492, 2011.

[15] B. Hannon, P. Sergeant, and L. Dupre, "2-D Analytical subdomain model of a slotted PMSM with shielding cylinder," IEEE Transactions on Magnetics, vol. 50, no. 7, pp. 1-10, 2014.

[16] F. Dubas and C. Espanet, "Analytical solution of the magnetic field in permanent-magnet motors taking into account slotting effect: no-load vector potential and flux density calculation," IEEE Transactions on Magnetics, vol. 45, no. 5, pp. 2097-2109, 2009.

[17] Z. Q. Zhu, L. J. Wu, and Z. P. Xia, "An accurate subdomain model for magnetic field computation in slotted surface-mounted permanent-magnet machines," IEEE Transactions on Magnetics, vol. 46, no. 4, pp. 1100-1115, 2010.

[18] A. Bellara, H. Tiegna, Y. Amara, and G. Barakat, "On load analytical modelling of the magnetic field for axial flux surfaceinset permanent magnet machines with semi-closed slots," in
Proceedings of the 20th International Conference on Electrical Machines (ICEM '12), pp. 2852-2858, Marseille, France, September 2012.

[19] Z. J. Liu and J. T. Li, "Analytical solution of air-gap field in permanent-magnet motors taking into account the effect of pole transition over slots," IEEE Transactions on Magnetics, vol. 43, no. 10, pp. 3872-3883, 2007.

[20] B. L. J. Gysen, K. J. Meessen, J. J. H. Paulides, and E. A. Lomonova, "General formulation of the electromagnetic field distribution in machines and devices using fourier analysis," IEEE Transactions on Magnetics, vol. 46, no. 1, pp. 39-52, 2010.

[21] S. Ouagued, Y. Amara, and G. Barakat, "Comparison of hybrid analytical modelling and reluctance network modelling for predesign purposes," Mathematics and Computers in Simulation, vol. 130, pp. 3-21, 2016.

[22] L. J. Wu, Z. Q. Zhu, D. A. Staton, M. Popescu, and D. Hawkins, "Comparison of analytical models of cogging torque in surfacemounted PM machines," IEEE Transactions on Industrial Electronics, vol. 59, no. 6, pp. 2414-2425, 2012.

[23] A. Hemeida, P. Sergeant, and H. Vansompel, "Comparison of methods for permanent magnet eddy-current loss computations with and without reaction field considerations in axial flux PMSM," IEEE Transactions on Magnetics, vol. 51, no. 9, article 8107511, 2015.

[24] H. Vansompel, P. Sergeant, and L. Dupre, "A multilayer 2-D2-D coupled model for Eddy current calculation in the rotor of an axial-flux PM machine," IEEE Transactions on Energy Conversion, vol. 27, no. 3, pp. 784-791, 2012. 


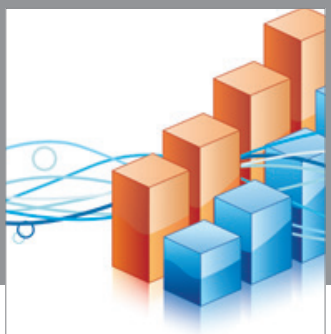

Advances in

Operations Research

vatem alat4

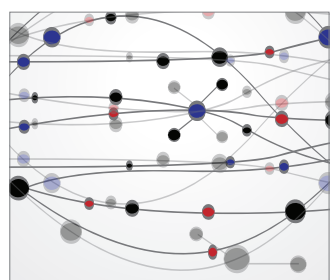

\section{The Scientific} World Journal
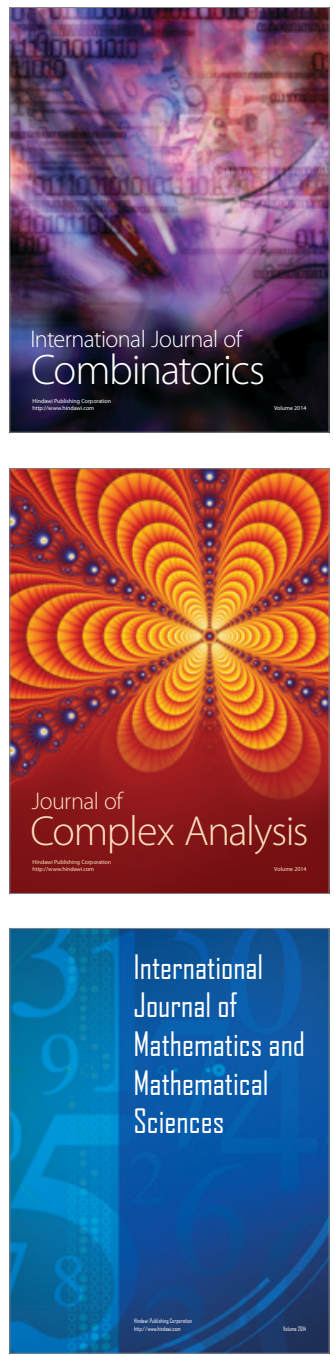
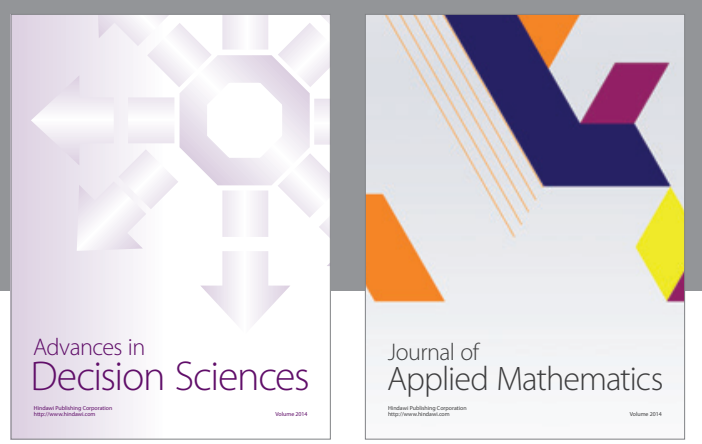

Algebra

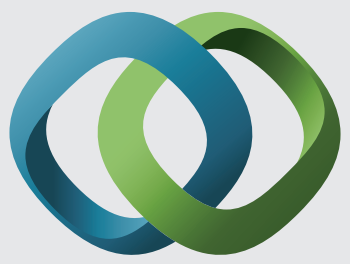

\section{Hindawi}

Submit your manuscripts at

http://www.hindawi.com
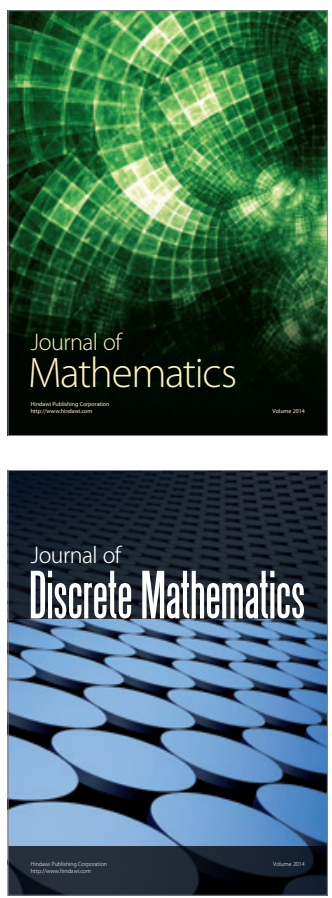

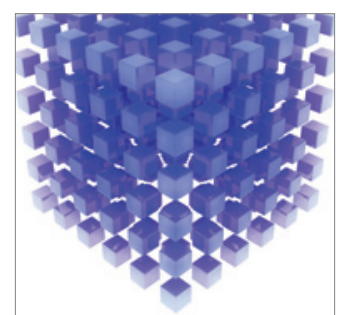

Mathematical Problems in Engineering
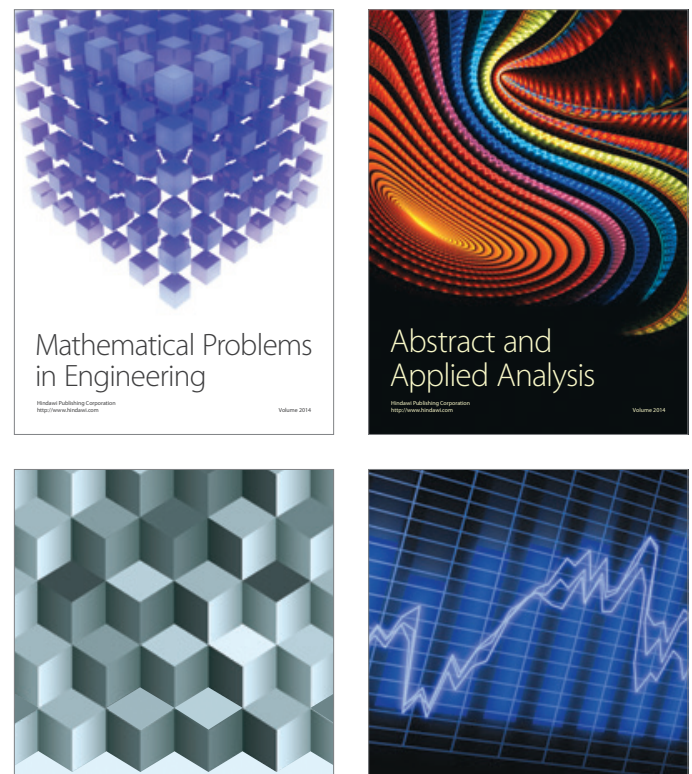

Journal of

Function Spaces

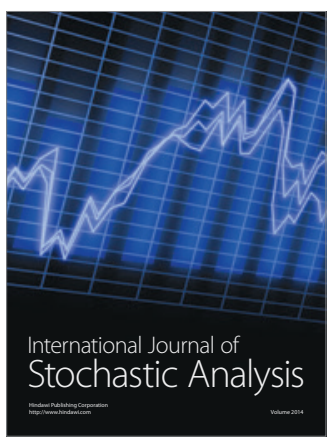

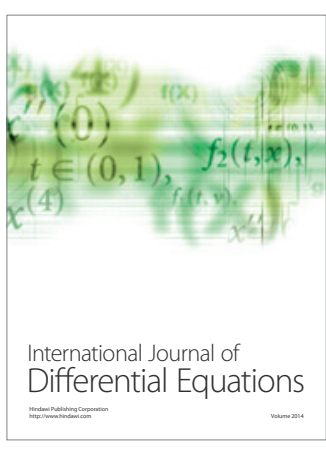
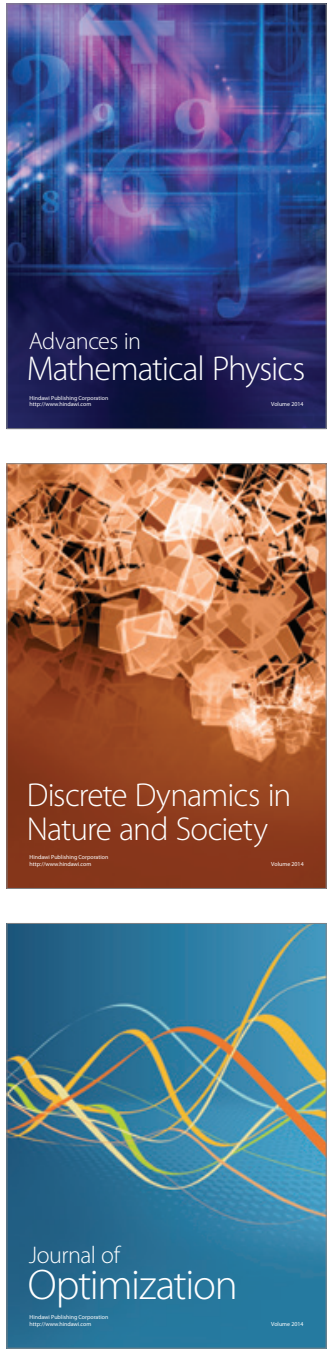